\title{
The Enigma of Identity of the Anglo-Indian Women in Shyam Benegal's Junoon (1978).
}

\section{Somdatta Halder}

Assistant Professor, Department of Film Studies, West Bengal State University, Kolkata, India

Mail Id: somdatta@wbsu.ac.in | ORCID ID: 0000-0002-0677-2808

\begin{abstract}
Jean-Paul Sartre argues that human beings are consisted of 'being' and 'nothingness'. They do not bear, unlike nonhuman entities, any predecided meaning or purpose of existence. Rather, they play roles to fashion their 'self' and thereby obtain an essence of their being. Though, to be recognized as a 'self' the social being requires the look of the 'other', Georg Wilhelm Friedrich Hegelremarks that the relation of self/other is not simply that of mutual recognition. Rather, it stimulates the primitive urge of dominating the other. This ambiguous relation of self/other is the central theme of the veteran Indian director Shyam Benegal's feature film Junoon. The paper probes into the enigma of identity of the Anglo-Indian women in the concerned film and subsequently addresses such aspects as the Sartrean notions of role-play and bad faith, the influence of the 'other' as the look in the identity crisis of the Anglo-Indian women, representation of different cultures in the film, the contradicting elements of cultural enmity and co-existence, and so on.
\end{abstract}

Keywords: Anglo-Indian Identity, Identity Crisis, Role-Play, Other as the Look, Self/Other

\subsection{Introduction}

Role-Play is a salient feature of human beings, argues Sartre, in terms of which they fashion their personae or 'self'. However, the process of self-formation remains incomplete without the presence of the 'other' as the look. Again, it is the look of the 'other' that robes the free 'self' from its innate nothingness. Thus, following Sartrean philosophy, the 'self' and the 'other' are perennially engaged in the struggle of survival. In Hegel's opinion this fundamental struggle splits the entire society in two rival classes: the dominant/self and the repressed/other. The paper explores the uneasy relation of self/other in the film Junoon by Shyam Benegal. The film was made in the year 1978, a time when the post-Independence India, after the period of Emergency (1975-77), was looking for certain aesthetic criteria that would define the new Indian Cinema, such as: "human interest in theme, Indianness, and characters with whom the audience can identify" (Ashish, 1998, p. 27). In 
Lunoon, Shyam Benegal revisits the historical epoch of Sepoy Mutiny (1857) in pre-Independence India and depicts the story of crises and survival of the women of the Anglo-Indian Labadoor family during the unrest. However, apart from the traumatic experiences of Ruth and her family, the narrative highlights the themes of cultural plurality and tolerance in India as well. The reading of the film in this paper combines the philosophies of Hegel and Sartre with the visual language of cinema.

\subsection{The Sartrean Notion of Role-Play}

Joseph S. Catalano observes in his book A Commentary on Jean-Paul Sartre's "Being and Nothingness" that according to the philosophy of phenomenology, the world exists as a meaningful whole owing to human perception and recognition. Human beings behold the world with curious eyes and impose meaning on everything they observe, though they themselves lack definite essence or a particular purpose of existence. That is why a man is a man not in the sense a pen is a pen. Driven by the urge to acquire meaning, according to Jean-Paul Sartre (1905 - 1980), an individual plays role to make his/her appearance evident and meaningful as a 'self'. In this context Catalano remarks that the innate nothingness of human beings, as opined by Sartre, bestows on them the freedom of an artist to fashion their personae. However, Sartre further argues that role-play of the 'self' becomes meaningful by being recognized by the 'other(s)'. Through recognition the 'self' seeks to achieve a meaning of his/her being and aspire to articulate the ' $\mathrm{I}$ '. That is to say, for the visibility of the 'self' as a persona with particular traits, the look/recognition of the 'other' is required.

\subsection{The Binaries of Self/Other}

In his book Subjectivity Donald E. Hall notes that from the theoretical perspective ofGeorg Wilhelm Friedrich Hegel (1770 - 1831), the look of the 'other 'shares an ambiguous relation with the 'self'. On one hand, the 'self' requires the 'other' for acknowledgement and thereby obtaining meaning in apparently meaningless life. On the other hand, the objectifying look of the 'other' robes the individual from its innate liberty of fashioning the essence/self according to the individual's own choice. Thus, the 'other' as the 'look', Hegel argues, intends to dominate the 'self' by externally imposing an identity on the object in the form of gaze.

Resembling Hegel's argument, Sartre recognizes the moment when the 'self' meets the 'other' as a situation of conflict. Elaborating Sartre's vision Catalano explains that the 'self' is objectified due to the presence of the 'other', and therefore, descends from the position of subject to object. That is why, in his argument Sartre imagines the moment in the first place as the confrontation between two 'self's, instead of the 'self' and the 'other'. These two 'self's are perennially engaged in conflict to win the contest of survival by dominating the other-self as the 'other'. In Hegel's opinion, this perennial struggle between the 'self' and the 'other' splits the entire structure of society in two fundamental rival groups, or, 'classes': the dominant/self and the repressed/other. Regarding this fundamental division, Donald E. Hall comments: "this uneasy dependence on the other leads to a form of "life-and-death" conflict from which, finally, one of the two beings (or, as a broad social metaphor, groups of beings) emerges as a victor and establishes a temporary master/slave relationship with the dominated other" (ㅂall, 2004, p. 51).However, he 
further notes that the apparent established master/slave relationship is never static. It always bears the threat of conflict between the two fundamental rival classes, which would result in a new synthesis: a new state of order.

\subsection{The Instability of Identity of the Eurasian Women}

The ambiguous relation of self/other appears to be the very leitmotif in the film Junoon or Obsession, directed by Shyam Benegal. It is an adaptation of Ruskin Bond's novella A Flight of Pigeons (1978). The story is set against the backdrop of the Sepoy Mutiny (1857) in India: a time when the preexisting positions of the ruler and the subject falls apart. During this chaos, Ruth Labadoor (Nafisa Ali), an Anglo-Indian young girl, loses her father in the hands of the rebels. Eventually, the poor girl, along with her mother, Miriam (Jennifer Kendal), and aged grandmother (Ishmat Chugtai), is held captive by a local Rohilla Pathan, Javed Khan (Shashi Kapoor). Javed is obsessed with Ruth's beauty and is adamant to marry her. In doing so he claims to protect Ruth and her family from being slaughtered. However, his proposal is strongly opposed by Ruth's mother. The narrative goes on to illustrate the rising conflict between Javed Khan and Miriam Labadoor, in correspondence with the chronological progress of the Mutiny.

Identity crisis is a central theme of the diegetic conflict between Javed, the representative of the indigenous culture, and Miriam, who represents the colonial community in India. The crisis essentially derives from the sense of insecurity of the Anglo-Indian woman. In the entire film the role of Miriam reverberates the anxiety that whether their Anglo-Indian identity is equivalent to that of the colonial superiors, or not. Quoting Alexius Pereira, Robyn Andrews remarks in his essay "Is the Anglo-Indian 'Identity Crisis' a Myth?" in the book Anglo-Indian Identity: Past and Present, in India and the Diaspora:

Anglo-Indian Eurasians in India in the 18th and 19th centuries were heavily discriminated against both by the British and the Indians because their hybridity was perceived to be a 'moral flaw' or 'dilution of the strong blood' (Gist and Wright 1973) by both the parent groups. As a result, the Anglo-Indians were forced to become self-reliant, and eventually formed a tight-knit social group of their own. - (Andrews, 2021, p. 117)

In Junoon as well, it is the cultural hybridity of the women of the Labadoor family that denotes the uncertainty of their colonial identity and stimulates the anguish of their social demarcation. The fourth sequence of the film (13:55) highlights the hybrid cultural root of the women of the Labadoor family. The episode opens at the dining table in Labadoor's bungalow where the grandmother, on one hand, prepares for the celebration of Eid, a Muslim festival, and orders the khansama (cook) to prepare sheer khurma1, and on the other hand, she becomes alarmed by the news of the upsurging revolt of the native soldiers against the British officers of East India Company and thereby she forbids her granddaughter from visiting the church next day. The cultural dichotomy is discernibly prominent in the role of the grandmother as she has been integrated in the domain of colonial culture only in terms of matrimonial rights. The narrative informs us that Miriam's mother, who

${ }^{1} \mathrm{~A}$ traditional dessert in Islamic cuisine. It is especially prepared to celebrate the festival of Eid. 
was married to a British officer, is a Muslim woman from the Nawab family of Rampur. Her adherence to the indigenous culture is emphasized in the narrative principally through her attire and language. In the course of the film, she appears clad in kurta and dupatta: the traditional dress of Muslim women which is worn as well by the other Muslim female characters in the film. Again, she also resembles them by speaking Urdu influenced Hindi, instead of the language of the colonisers. Hence, the language demarcates her from the rest of the Labadoor family. In contrary to her, Miriam is the progeny of the racially distinct parents, and thereby, she is interpellated in the sphere of the European colonisers as the Anglo-Indian woman by birth. Her in-between racial status is reflected in the text in terms of her moderate knowledge of her mother's native language. In fact, during the concerned episode she plays the role of the intermediary between her mother and her husband, who are linguistically different from each other. Again, Miriam, the Eurasian woman, is married to Mr. Labadoor (Tom Alter), a British patriarch. Subsequently, Ruth, their daughter, does not inherit her grandmother's native language. It is suggested in the narrative that though she might understand Hindi, she is almost unable to speak in it. Rather, she adopts the colonial language, like her British father. The linguistic transition of the three generations of women of the Anglo-Indian family in Junoon, therefore, reveals the phenomenon of their self-formation as an aspect of social upgradation and a means of earning respectability. The transition represents Miriam's denial to accept her connection with the indigenous culture, as if it is a flaw of her identity: a perspective which is enhanced later in her conflict with Javed Khan regarding Ruth's marriage. On the context of identity formation and identity crises of the Anglo-Indian individuals, Robyn Andrews refers to Erik Erikson's thesis and asserts:

Identity formation normatively has its negative side which throughout life can remain an unruly part of the total identity. The negative identity is the sum of all those identifications and identity fragments which the individual had to submerge in himself as undesirable or irreconcilable or by which atypical individuals and marked minorities are made to feel 'different'. In the event of aggravated crises, an individual (or, indeed, a group) may despair of the ability to contain these negative elements in a positive identity. -( $\underline{\text { Andrews } 114)}$

Likewise, her relationship with the indigenous culture is considered by Miriam as the undesirable fragment of her colonial identity. That is why she wants her daughter to be internalized in the colonial space as the white European woman, permanently departed from the traces of Asian identity. Ruth's adoption of the language of the colonisers represents her, and especially, her mother's fidelity towards the superior culture and thereby appears to be the signifier of their cultural upliftment. Hence, it can be argued that in Junoon Miriam is in bad faith ${ }^{2}$ as she intends to play the role of the respectable wife of the British patriarch and the mother of the white colonial woman with sincerity, ignoring the counterpart of her cultural root, and in doing so she aspires to establish her belongingness among the superior colonisers. The episode closes with the depiction of

2Sartre identifies 'bad faith', as Joseph S. Catalano notes, as a notion of self-denial, or rather, the act of deceiving the 'self'. He further elaborates the idea and says that to deny something we consciously admit it as fact in the first place. Then, the image of that fact is to be replaced by an alternative possibility, and therefore, the alternative fact is to be believed as the temporal reality. 
the state of order that retains the hierarchy of colonisers/subordinates inside the residency of the Labadoor's, in contrary to the news of revolt in the outside. The long shot (15:40) features the entire hall which is visually segregated in two parallel spaces. In the left, the Labadoor family begins to have dinner at the dining table, whereas at the right side of the frame their native servants are standing looking at them for further instruction. The look of the subordinates and their subsequent subservience, as emphasized by the shot of the pankha puller (15 minute 45 second), objectifies the Anglo-Indian family as the superior colonisers.

\subsection{The Battle of 'Look'}

The choice of playing the role of the respectable colonial woman becomes uncertain when Ruth becomes exposed to the gaze of Javed Khan. In the film, the character of Ruth is developed not as a vocal figure, unlike her mother, but a perceiver. She recognizes Javed as a threat to the acquired respectability of the Anglo-Indian women, for, his intrusion in the colonial space stimulates their anguish of losing the granted cultural privilege of the European 'self'. In the first part of the film, he intrudes in the colonial space as a voyeuristic onlooker. The first iconic moment of looking at the other-as-object occurs at 09 minute 57 second. The sequence begins with an extreme long shot featuring the exterior of the Labadoor's bungalow. Soon the camera tracks back to capture a closeup of Ruth. The mise-en-scéne of the frame suggests that she is inside the premises of the bungalow. The close-up is followed by a point of view shot that reveals the object that Ruth is looking at, that is, Javed Khan, the Pathan. At this point, the camera once again resumes back to the extreme long shot to inform us that he is standing outside of the gate, far away from Ruth. The physical distance between the two figures intensifies the social distance of the cultural others, as well as it suggests that Ruth is still secured in the colonial space, from the approaching danger. The following frame features a medium close-up of Javed Khan, who is looking back at Ruth. Therefore, the concerned scene becomes the iconic moment when the two independent selves are looking at each other with the intention to objectify or dominate the other, as argued by Sartre. Eventually, Javed dominates the sequence as the pervading look, and thereby controls the objective appearance of Ruth. Her objectification by Javed as the look, resonates the Sartrean notion of losing the free 'self' following the look of the 'other'. As Catalano comments, Sartre remarks in this context that "The other, as the look, alienates me from my possibilities, removing me from that original innocence by which the instrumentality of things is an embodiment of my freedom. By the other's look, I am fixed within the world; things no longer have a simple relation to me; rather I and my situation are related to him as his instruments. Further, I am aware of this and recognize myself as now being in the world with my possibilities objectified and fixed by him" (Catalano, 1985, p. 162). Resembling his argument, in Ruth's next close-up, the camera accentuates her expression of anxiety reflecting her awareness of being looked-at. At that moment, Javed's look overpowers her freedom of possibilities and fixes her appearance as the vulnerable white woman: the erotic object of the racially inferior indigenous other's desire. Therefore, the imposed objectifying gaze of Javed Khan problematizes Ruth's fidelity towards the colonial culture. However, in this connection we should note what Sartre argues regarding the resistance of the self-being-looked-at to escape from the limitation imposed by the other-as-the-look. Sartre is of opinion, as explained by Catalano, that "It is because of our emotions such as fear and shame that we attempt to turn the other-as-subject into 
the other-as-object" (Catalano, 1985, p. 163). Likewise, overwhelmed by her sense of insecurity and fear to lose the position of the cultural superior, Ruth looks back at Javed and objectifies him as a threat on her selfhood, a usurper. Thus, in the concerned situation she posits her 'self' as the precarious victim in front of the oppressive onlooker. Javed's objectified image continues to haunt Ruth in her nightmares. Thereby, such sequences emerge in the film as the symbolic representation of the antagonistic relation of the 'self' and the 'other'.

In the course of the narrative, Ruth continues to objectify the cultural other in the sequence of church massacre as well. In this episode of violence (19:34) Ruth is not only posited as the eyewitness of the incident, rather the entire scene is depicted from her perspective. The church sequence begins at 17 minute 57 second with a premonition of the impending danger, when Ruth, along with her father, leaves the house to visit the church. Here, Ruth becomes vulnerable once she leaves the bungalow where, as it is previously said, the hierarchy of colonisers/subordinates prevails, and comes outside in the external space where the status quo is already disrupted. In the concerned frame we observe Ruth in the same place where Javed Khan, the signifier of threat, was standing in the erstwhile frame, that is, outside the gate of the bungalow. Her mobility towards the right corner of the frame is interrupted by the arrival of three native soldiers from the opposite direction, who look back at her. This sudden intrusion, along with her state of exposure, increases the probability of strike from the 'enemy'. The native soldiers are marked as the opponents in this scene as Mr. Labadoor embraces her daughter as a gesture of guarding her from their sight. The tension persists even during the sequence of prayer. The scene of church service is composed in frequent long shots and deep focus, that highlight the old clergyman, women, children, and civilians in the gathering. In the concerned frame these figures are exposed as precarious beings, unaware of the forthcoming onslaught. The prayer is interrupted at 20 minute 04 second when a group of Indian soldiers break into the hall. To compose the situation of violence, the director has used frequent close-ups following the pattern of montage. The series begins with the close-up of Sarfaraz Khan (Naseeruddin Shah), the leader of the local rebels and Javed Khan's brother-in-law. His aggressive entry is followed by the close-up of horrified, shrieking Ruth. The slaughter of British civilians and army, including the death of Mr. Labadoor and the beheading of the old priest by Sarfaraz Khan, is captured in point of view shot where, following the perspective of Ruth, Sarfaraz is objectified as another usurper: the murderer. Therefore, in Junoon, the appearance of Sarfaraz Khan becomes the symbol of the external threat, i.e., the furore of the Mutiny that jeopardized the authority of the colonisers, in parallel with the portrayal of Javed Khan as a personal threat, who provokes the crisis of identity in the Anglo-Indian women of Labadoor family. The external threat overlaps with the personal one in the chasing sequence (22:10). In this episode the scared Ruth returns to her house only to find that it is on fire. Meanwhile, Lala Ramjimal (Kulbhushan Kharbanda), a local Hindu merchant and a friend to the Labadoors, comes to her rescue. They try to reach the place where her mother and grandmother are hiding. Here, the appearance of Javed Khan who is looking for Ruth, and the image of the rebel soldiers who are after the left Europeans, are objectified as the oppressive onlooker. The visibly distressed Ruth seeks to escape from the look of both the figures. Again, the symbols of external and personal threats merge together in the sequence of Ruth's delirium (36:44). The sequence opens with the rally of the native 
soldiers led by Sarfaraz Khan, celebrating their victory. The following shot reveals that the scene is being watched by Ruth, Miriam, and the grandmother, who are given shelter by Lala Ramjimal. Recognizing Sarfaraz as the murderer, Ruth loses her nerve. Meanwhile, Kader Khan (Jalal Agha), an associate to the Khan brothers, visit Lala Ramjimal's place and recounts the gruesome incidents of the church massacre. Traumatized by the vision and the description, Ruth imagines Sarfaraz and Javed as two alternative oppressors who are assaulting an innocent girl, which is, probably, the optical suggestion of the vulnerability of Ruth herself. Ultimately, at 53 minute 32 second the chase ends with the exposure of the Anglo-Indian women before the look of the aggressive oppressor, as Javed Khan intrudes in the house of Lala Ramjimal and abducts them to his place.

\subsection{The Imposed Suspicion of Infidelity for being Anglo-Indian}

As an impact of the external crisis, the previous state of order and the subsequent hierarchy of colonisers/subordinates which was evident in the colonial space during the dining sequence, collapses after the death of the British patriarch. Following his death, the identity of the AngloIndian women becomes a matter of question and eventually they turn to be the objects of the look of suspicion. The transition becomes evident in the sequence which occurs at 31 minute 04 second. In this sequence Lala Ramjimal brings the homeless Labadoor women in her house to give shelter, to the dismay of his mother. Entering in the house, the Anglo-Indian women become the object of look of the female members of Ramjimal's family. Significantly, the spatial division of the former frame, suggesting the discrimination of colonisers/subordinates, is visibly absent in the composition of the concerned sequence. Rather, we observe that the Anglo-Indian women are standing together with the native subjects. At this phase of the narrative, the look of the indigenous characters, who have been previously demarcated as the inferior servants, objectifies the Eurasian women as the untouchable 'others', instead of the superior colonisers. Eventually, their imposed identity as 'firangan' (the woman who is an exotic outsider) raises question regarding the respectability and fidelity of the Anglo-Indian women from the perspective of the indigenous subjects. The constant suspicion compels Miriam to play her role as the respectable widow of the British patriarch and the protective mother of the European woman, with even more sincerity. In doing so she intends to resist the suspicious look of the others. Incidentally, it is Ruth who first bears the suspicious look towards her mother in the course of the narrative. The sequence opens at 40 minute 43 second with the sudden arrival of Javed Khan at Ramjimal's house with the intention to verify Kader Khan's information that the women of the Labadoor family are given shelter by Ramjimal. However, for the time being Ramjimal succeeds to control the situation and Javed Khan leaves his house, disheartened. Miriam was eagerly waiting for his departure and once he leaves, she requests Ramjimal to come upstairs in their room. Meanwhile the camera features Ruth and informs us that she too is present in the room, looking after her ailing grandmother. Ramjimal's entry in the room and his conversation with Miriam is composed in tight frame that enhances the increasing physical proximity of the two cultural others. In this shot Miriam appears as visibly disturbed by Javed Khan's visit and she thinks to leave the place soon for the sake of their security. She asks for Lalaji's favour to reach her maternal relatives in Ramgarh. However, Lala Ramjimal assures her that no harm can touch them as far as they are his guests. At this moment their proximity further increases as Ramjimal holds her hands and utters: "Mujhpar bharosa rakkhiye" ("Trust me"). For that moment 
it appears that the hierarchy of dominant coloniser and indigenous subordinate has fallen apart, which refers to the possibility of Miriam's infidelity ${ }^{3}$ in the absence of the British patriarch. Following the sensitive moment, the camera shifts back to Ruth and reveals that Ramjimal's action of holding Miriam's hands is being looked at by her, as if the digression of the Anglo-Indian woman is being watched by the European woman, as a representative of the colonial culture. Her suspicious look stimulates Miriam's consciousness of being looked at and she, almost instantly, withdraws her hands from Ramjimal's, denying the chance of infidelity. The significance of Ruth's presence in the scene as the pervading look is emphasized as the episode closes with Miriam and Ramjimal looking back at her, reflecting the awareness of being revealed.

However, the identity of infidel woman is forcibly imposed on Miriam by the look of Firdaus (Shabana Azmi), Javed Khan's wife. In this sequence (56:57) Lala Ramjimal comes to visit Miriam Labadoor, after their abduction by Javed Khan, to return her jewellery box. He secretly informs her that he is leaving for Bareli soon, along with his family, and there he would try to inform Miriam's brother about their plight. The action takes place in the courtyard of Javed Khan's haveli. The scene is eventually intervened by the entry of Firdaus. She watches the aforesaid action from the veranda of the first floor of the building. Though the concerned figures are unaware of her presence, their appearance as objects-being-looked-at is established through the high angle shot (57:56). At the time of final departure, Miriam holds Ramjimal's hands as a gesture of gratitude ${ }^{4}$ and also as an expression of her fear for their uncertain future, which is recognized by Firdaus as the improper act' of the infidel firangi woman ${ }^{5}$. Unlike the former sequence, here Miriam is not left with possibilities to choose. Rather, her persona is determined by the gaze of the 'other'. The sequence visually suggests that from this moment the Anglo-Indian women lose their liberty to shape their own selves. Instead of that, they turn to be the objectified others, as fashioned by the look of the indigenous oppressive onlooker.

\subsection{The Oppressive 'Other' and the Defence of the 'Self'}

The notion of oppression becomes prominent in the film when Javed Khan gives the proposal to marry Ruth. His proposal increases the possibility of permanent departure of the Eurasian woman

\footnotetext{
${ }^{3}$ Here, the word 'infidelity' refers to the possibility of Miriam's distraction from playing the role of the widow of the British patriarch with authenticity, and thereby representing the colonial culture.

${ }^{4}$ According to Shyam Benegal, as told to William van der Heide in the interview for Bollywood Babylon, the role of Lala Ramjimal in Junoon significantly portrays the ambiguous relationship that the Indians shared with their British colonisers. His presence highlights the 'give and take policy' undertaken by both the groups. He further remarks that the different approach of Ramjimal and several Muslim characters in the film, towards the women of the Labadoor family, is not deliberately depicted as a communal issue, but it eventually turns to be so. Benegal asserts: "It was also a question of who was gaining from the British at the time. Ramjimal was somebody who dealt with them on a business level, while the Pathans had nothing to do with them. . After the revolt was quelled, the British decided that they were going to change the whole social scheme of things so that this would never happen again. They actively encouraged the Hindu community to get themselves a British education. In response certain Muslims, despite opposition from within the Muslim community, argued that Muslims should also accept an English education, in order to stop the Hindus from taking over. The British always played one side against the other" (Heide 98).

${ }^{5}$ Later, she shares her perception with her husband (59:34) and thereby appears to fix Miriam's Identity.
} 
from the domain of superior colonisers, and her subsequent relocation among the inferior colonized. Ruth's departure from the position of superiority would establish Miriam's failure in playing her role as the Anglo-Indian mother of the colonial woman with enough sincerity. To intensify Miriam's sense of insecurity, the narrative implements forceful transition in the appearance of the Anglo-Indian women. In the concerned episode (01:04:45) where Javed Khan proposes Ruth to marry, he also declares that the women of Labadoor family have to follow the traditional dress code of respectable Muslim women in his house. Therefore, control over the appearance of the objects becomes the fundamental instrument of the oppressive indigenous patriarch and the onlooker to enforce them to subjugate before his authority. The gaze of the 'other', thus, is imposed on the Anglo-Indian women in Junoon that coerces them to perform the role of indigenous women, obeying Javed Khan's choice. That is why, the close-up of Ruth (01:23:26) decorated in dupatta and ethnic jewelleries, bears Miriam's anguish of social degradation of the colonial feminine subject. Subsequently, it can be argued that both Javad Khan and Miriam Labadoor objectifies Ruth's appearance in order to predetermine the role that she should play. The battle in the domestic space begins, parallelly with the Mutiny outside, regarding the question that whether Ruth would adopt the cultural code of the Muslim patriarch, or, she would continue to play the role of the cultural other who recognizes Javed Khan as a threat on her acquired superiority. However, both of them overlook the fact that their objectification curtails her freedom as a 'self'. In that sense, both the figures play the role of the oppressive onlooker who intend to decide how Ruth should look. In the course of the narrative Miriam makes her stand of opposition clear at 01-hour 23 minute 18 second, as she asserts: "Dushman ki niyat hamesha buri hoti hai" ("Enemy's intention is always in question"). To resist the enemy's strike, Miriam's anguish is redirected as repulsion, and she objectifies Ruth's appearance in ethnic outfit as that of a "nautch girl"6: the degraded identity of indigenous amoral woman.

\subsection{Conclusion}

Our study, therefore, reveals that from the reciprocal aspects of 'look', i.e., looking-at and beinglooked-at, derives the antagonistic relation between the 'self' and the 'other'. However, following this antagonistic relation, the dialogue between the subject and the object begins to develop in Junoon. The probability of negotiation regarding the coexistence of the two cultural others first appears when the narrative shifts (01:13:29) to Javed's chachijaan (Sushma Seth) or aunt's haveli. The entry of the Anglo-Indian women in chachijaan's house is followed by the formation of a feminine domain in the narrative, where the masculine oppressive onlooker is absent. The feminine domain appears on the screen at 01-hour 14 minute 13 second with the extreme long shot of mango orchard, which is the natural space of organic growth. Eventually, in this sequence the use of diegetic songs significantly emphasizes the temporary freedom of the Anglo-Indian women from the dominant objectifying gaze of the other. The episode begins with the Hindi song "Sawan ki aayi bahar re" sung by chachijaan's daughter-in-law (Deepti Naval). Regarding the song and the scene Shyam Benegal comments in Bollywood Babylon, "That is a song that is always sung at Shravan, which is the second

${ }^{6}$ The phrase refers to the traditional Indian women performers or courtesan. 
month of the monsoon. Then Ruth's mother sings a little song from Shakespeare. The scene shows the meeting points of different cultures. It was an opportunity to look at different cultures and also to look at the essential plurality of Indian culture" (Heide, 2006, p. 99). Unlike the former sequences which took place in the cultural space of Javed Khan's haveli, here, Ruth and Miriam appear free to choose to play the role of European self. The coexistence equally prevails in the sequence of the last rituals of Ruth's grandmother. After her mother's demise, Miriam expresses her desire to bury her mother following proper Christian code. The sequence is composed almost as a Utopian restoration of order. Here, in contrary to the erstwhile sequence of church massacre where the prayer was interrupted by the encroachment of the native rebels, Miriam completes the ritual. At this moment, the reciprocal action of looking-at and looking-back reoccurs in the film. In the sequence (01:46:53), the camera at first captures a medium close-up of Javed Khan who is looking at Ruth, standing next to him. In the following frame Ruth returns the look back at him. In response, Javed lowers his eyes. It becomes the iconic moment when the subjective onlooker becomes the object of the look. The sequence closes with Ruth as the look, who re-recognizes Javed Khan as an ambiguous figure: a threat to her freedom of being, as well as a compassionate lover. The sequences of cultural coexistence in Junoon, therefore, are depicted as moments of plentitude. The cultural coexistence, on one hand, refers to the innate hybridity of the Anglo-Indian free 'self' in the narrative, as well as it relocates the cultural plurality of post-Independence India on the screen. Probably that is why, though the film ends with the separation of the lovers and the news of Javed Khan's death in combat (as told in the voice over of Amrish Puri), Ruth's final decision to remain unmarried reverberates the hope of cultural union.

\section{References}

Andrews, Robyn. "Is the Anglo-Indian 'Identity Crisis' a Myth?" Robyn Andrews, Merin Simi Raj. AngloIndian Identity: Past and Presesnt, in India and the Diaspora. Switzerland: Palgrave Macmillan, 2021. 111-130. ebook.

Ashish Rajadhyaksha, Paul Willemen. Encyclopaedia of Indian Cinema. New Delhi: Oxford University Press, 1998.

Catalano, Joseph S. A Commentary on Jean-Paul Sartre's "Being and Nothingness". Chicago: The University of Chicago Press, 1985. Book.

Hall, Donald E. Subjectivity. New York: Routledge, 2004. Book.

Heide, William van der. Bollywood Babylon: Interviews with Shyam Benegal. Oxford: Berg, 2006. Book. Junoon. Dir. Shyam Benegal. Perf. Shabana Azmi, Naseeruddin Shah, Nafeesa Ali, Jennifer Kendal Shashi Kapoor. 1978. CD.

Somdatta Halder is an Assistant Professor, Department of Film Studies, West Bengal State University, Kolkata, India, Ph.D. Scholar, Department of English, University of Calcutta, Kolkata, India 